\title{
Implantação do Cadastro Territorial Multifinalitário no Brasil
}

\author{
Implantation of Multipurpose Territorial Cadastre in Brazil
}

\author{
Jacir Antônio Rambo ${ }^{1}$ \\ Luiz Inácio Rambo ${ }^{2}$ \\ ${ }^{1}$ Instituto Brasileiro de Cadastro e Gestão Territorial - IBC \\ Cep 88040-900. Florianópolis, SC, Brasil. \\ ${ }^{1}$ Curso Técnico Subsequente em Agrimensura, Instituto Federal de Santa Catarina - IFSC \\ Campus Florianópolis. Cep 88020-300. Florianópolis, SC, Brasil. \\ jacirrambo@bol.com.br
}
${ }^{2}$ Departamento de Agrimensura, Universidade Tecnológica Federal do Paraná - UTFPR. Via do Conhecimento, km 1 Campus Pato Branco. Cep 85803-390. Pato Branco, PR, Brasil.
inacio@utfpr.edu.br

\begin{abstract}
RESUMO - O propósito do presente trabalho é esclarecer a necessidade de reformas no sistema imobiliário cadastral. Visa facilitar a gestão territorial e solucionar problemas burocráticos que entravam o desenvolvimento do país. A questão principal diz respeito a tentativas frustradas para se criar uma cartografia para o Cadastro de Imóveis Rurais em meio a uma confusão doutrinária entre os termos Registro e Cadastro, cartografia e georreferenciamento, cadastramento e retificação. Aborda questões controversas como grilagem de terras e sobreposição de registros territoriais. $\mathrm{Na}$ análise do trabalho, conclui-se que a reforma é urgente e necessária ao desenvolvimento nacional: o Cadastro Territorial, para ser Multifinalitário, pode não se apresentar com alta precisão em toda sua extensão, mas precisa ser imediatamente cartográfico, contendo a continuidade de todas as parcelas pertencentes a cada município.

Palavras-chave: Cartografia, Cadastro Nacional de Imóveis Rurais, Cadastro Ambiental Rural, Georreferenciamento, Direito Imobiliário, Grilagem de Terras.
\end{abstract}

\begin{abstract}
The purpose of this study is to clarify the need for reforms in the immovable cadastre. Visa facilitate land management and solve bureaucratic problems that hinder the development of the country. The main issue relates to failed attempts to create a mapping for the Cadastre of Rural Realty amid doctrinal confusion between the terms Registry and Cadastre, Cartography and georeferencing, cadastration and rectification. It addresses issues such as land grabbing and overlapping territorial records. In job analysis, it is concluded that reform is urgently needed for national development: Territorial Cadastre, to be multipurpose, can not perform with high accuracy throughout its length, but must be immediately cartographic containing the continuity of all the plots belonging to each municipality. Keywords: Cartography, National Cadastre of Rural Realty, Rural Environmental Cadastre, Georeferencing, Immovable Law, Land Grabbing.
\end{abstract}

\section{INTRODUÇÃO}

No Brasil, a falta da cartografia cadastral de parcelas territoriais é antiga, a tal ponto que a propriedade sobre imóveis (direitos reais) foi legalizada em cartórios com direitos bem definidos sobre imóveis geralmente mal caracterizados, descritos inicialmente com base em dados declarativos e aproximados.

$\mathrm{Na}$ doutrina tradicional, Cadastro sempre foi vinculado ao mapeamento contínuo de todas as parcelas territoriais de uma determinada região. A falta desse cadastramento dificulta e até impede o planejamento para o desenvolvimento do país, já que é quase impossível um bom entendimento das informações que não estejam vinculadas a uma adequada representação de posicionamento espacial dos dados a serem analisados.

Com o tempo algumas doutrinas equivocadas são aceitas, aplicadas e assimiladas indistintamente na sociedade, impregnando-se de tal modo que em um importantíssimo evento internacional, especialistas tiveram enormes dificuldades para encontrarem conceitos que pudessem evitar a confusão existente entre os termos Registro e Cadastro (SIMPÓSIO INTERNACIONAL DE EXPERIÊNCIA FUNDIÁRIA, 1984).

Este trabalho tem por objetivo esclarecer determinados problemas técnicos, jurídicos e administrativos que entravam o desenvolvimento do mercado imobiliário em nosso país, relacionando-os com 
a confusão existente entre alguns conceitos vinculados ao Cadastro e/ou ao Registro.

Pretende abrir novos caminhos no setor imobiliário, apontando problemas ligados a confusões conceituais que, esclarecidas, possam facilitar a mudança de paradigma em direção à redução do Custo Brasil, o que poderá favorecer aos vários componentes da sociedade organizada.

\section{PROJETOS CADASTRAIS}

As terras no Brasil inicialmente passaram do Reinado/Portugal para o domínio privado através das Capitanias Hereditárias, cujos beneficiados estavam autorizados a distribuir as terras do respectivo território.

Posteriormente o governo determinou que as terras ainda não ocupadas deveriam ser devolvidas. O governo se declarou proprietário dessas terras devolutas, que estavam sujeitas a devolução. Em 1822 estabeleceu-se a época da posse, na qual cada um estava autorizado pelo governo a pegar para si as terras que lhes interessassem.

Em meados do mesmo século encerrou-se a época de aquisição pela posse, criando-se o Registro Paroquial, quando os interessados deveriam contar ao vigário, de modo aproximado, as terras que cada um possuía. O governo nunca soube ao certo quais foram as terras devolutas que lhe restaram.

Novas leis foram feitas determinando que também são do governo as terras ditas de marinha, bem como aquelas localizadas na faixa de fronteira. $\mathrm{Na}$ falta de cartografia, o governo não consegue definir totalmente o que lhe pertence.

A prometida reforma agrária não sai a contento e o governo nem sabe ao certo quais terras tem para distribuir. Muitos latifundiários não declaram seus imóveis ao Cadastro e ficam sem pagar o Imposto Sobre a Propriedade Territorial Rural - ITR e, nas descrições só literais, não se consegue saber onde ficam os imóveis. Ao constatar um imenso desmatamento, o governo enfrenta sérias dificuldades para definir o proprietário e tentar punir os culpados pela depredação.

Outra forma de adquirir a propriedade de imóveis é pela usucapião, baseada na posse mansa e pacífica sem contestação por determinados períodos. Mas depois de ser formalmente registrada, a propriedade poderá ser anulada, se posteriormente for constatado que a área é pública.

\subsection{Cadastro de Imóveis Rurais}

De acordo com o Estatuto da Terra (Lei 4.504/1964), cabe ao Instituto Nacional de Colonização e Reforma Agrária - INCRA a função de promover a realização de levantamentos cadastrais (Art. 46), o que pode ser realizado pelos municípios, devendo o INCRA aprovar as normas e as fichas que se fizerem necessárias para a organização dos Cadastros de imóveis rurais (Art. $46, \S 2^{\circ}$ ):

Art. 46 O Instituto Brasileiro de Reforma Agrária (Atual INCRA) promoverá levantamentos [...] para a elaboração do cadastro dos imóveis rurais em todo o país [...] (Observação nossa).

$\S 2^{\circ}$ Os cadastros serão organizados de acordo com normas e fichas aprovadas pelo Instituto Brasileiro de
Reforma Agrária (Atual INCRA) na forma indicada no regulamento, e poderão ser executados centralizadamente pelos órgãos de valorização regional, pelos Estados ou pelos Municípios, caso em que o Instituto Brasileiro de Reforma Agrária (Atual INCRA) lhes prestará assistência técnica e financeira com o objetivo de acelerar sua realização em áreas prioritárias de Reforma Agrária (BRASIL, 2007, p. 140-141) (Observações nossas).

A Lei 5.868/1972 instituiu o Sistema Nacional de Cadastro Rural - SNCR (Art. $1^{\circ}$ ), sendo que um de seus componentes é o Cadastro de Imóveis Rurais - CIR (Art. $\left.1^{\circ}, \mathrm{I}\right)$ :

Lei 5.868/1972, Art. $1^{\circ}-$ É instituído o Sistema Nacional de Cadastro Rural, que compreenderá:

I - Cadastro de Imóveis Rurais;

II - Cadastro de Proprietários e Detentores de Imóveis Rurais;

III - Cadastro de Arrendatários e Parceiros Rurais;

IV - Cadastro de Terras Públicas;

V - Cadastro Nacional de Florestas Públicas (BRASIL, 1972).

Através das Unidades Municipais de Cadastramento - UMC, o INCRA tem distribuído formulários vinculados ao SNCR e ao CIR, para que os proprietários ou detentores de imóveis rurais preencham a Declaração para Cadastro de Imóvel Rural - DP, exigindo apenas informações literais, sem necessidade de qualquer desenho do imóvel a ser cadastrado.

Em anexo ao formulário DP, a Diretoria de Cadastro e Tributação do INCRA tem fornecido o Manual de Orientação para o CIR vinculado ao SNCR. Na p. 4 de um desses Manuais de Orientação (sem data, por servir para mais de um ano) consta a informação de que "Detentores de imóveis com área total igual ou superior a 1.000,0 (um mil) hectares terão que anexar cópias de plantas e/ou memoriais descritivos." Mas ressalta:

Poderão também ser anexadas, em substituição ao memorial descritivo, certidões cartoriais de inteiro teor ou documentos de titulação, que contenham a descrição do perímetro e possibilitem a elaboração de planta do imóvel (BRASIL, 200-?, p. 4).

Assim, o Cadastro de Imóveis Rurais não tem cartografia contínua de todos os imóveis, sendo ainda formado por declarações literais e efetuadas através de formulários descritivos, aceitando-se quaisquer mapas, memoriais descritivos ou matrículas de imóveis que possam facilitar uma interpretação cartográfica à descrição do imóvel cadastrado.

Acertadamente o INCRA tem se preocupado em obter informações cartográficas que possam reduzir a enorme quantidade de imóveis rurais que ainda se encontram cadastrados apenas por informações literais. Por outro lado, observa-se que os profissionais da agrimensura e a academia tendem a se juntar com a doutrina cartorial, preocupando-se exageradamente com a precisão do georreferenciamento, por lei destinado especificamente ao aperfeiçoamento da descrição de imóveis no Registro.

A sociedade pode estar deixando para trás a preocupação com necessidades mais urgentes, como um Cadastro de menor precisão, mas com cartografia contínua, envolvendo todos os imóveis e com finalidades mais nobres, como o planejamento do desenvolvimento 
rural e o necessário incremento na arrecadação, através de um ITR que, na nossa visão, deveria ser municipalizado.

\subsection{Cadastro Nacional de Imóveis Rurais}

$\mathrm{Na}$ medida em que os gestores públicos e a sociedade permanecem confusos e desorientados por falta de uma cartografia cadastral que possa mostrar simultaneamente a continuidade de todos os imóveis, muitos latifundiários não pagam o ITR. Ao mesmo tempo, permanecem as atividades na grilagem de terras, na venda dupla de imóveis e na sobreposição de registros territoriais. Essa sobreposição de títulos chega ao ponto de se constatar que as áreas matriculadas em cartórios de Registro, podem somar mais área do que existe na superfície territorial da correspondente jurisdição.

$\mathrm{Na}$ Bahia chega-se a falar no registro de documentações de segundo, terceiro e até de quarto "andar". Se continuarmos sem uma cartografia sistematizada e contínua no Brasil, dentro de mais alguns anos talvez vamos precisar de elevador para poder analisar a confusão na publicação de documentos em alguns cartórios do país...

Mas a influência das grilagens vai muito além do que se pode imaginar inicialmente:
A Lei 10.267 originou-se na junção de dois fatos políticos importantes: o primeiro foi a pressão da comunidade internacional para que o país organizasse sua vertente rural, de forma a continuar a receber verbas internacionais; o segundo fato foi o trabalho desenvolvido pela Comissão Parlamentar de Inquérito da Câmara dos Deputados (CPI da Grilagem) que levantou o verdadeiro caos em que se encontra o sistema registral brasileiro. Como exemplo extraído dessa CPI pode ser citado o caso de Babaçulândia (TO), onde a área registrada dos imóveis representa o dobro da área do Município (PEREIRA e AUGUSTO, 2004, p. 2). (Destaque nosso).

Assim, a Lei 10.267/2001 acrescentou o $\S 2^{\circ}$ do art. $1^{\circ}$ da Lei 5.868/1972, criando o Cadastro Nacional de Imóveis Rurais - CNIR, a ser administrado pelo INCRA e pela Secretaria da Receita Federal, com a finalidade de regulamentar os procedimentos de retificação da descrição de limites, áreas e confrontações de imóveis rurais, numa tentativa de resolver a questão da grilagem. Esse CNIR ficou fazendo parte do SNCR, juntamente com outros cadastros oficializados e que estão funcionando em paralelo, tais como o CIR, o Cadastro de Terras Públicas e o Cadastro Nacional de Florestas Públicas:

Lei 5.868/1972, Art. $1^{\circ}$ - É instituído o Sistema Nacional de Cadastro Rural, que compreenderá: I - Cadastro de Imóveis Rurais;

II - Cadastro de Proprietários e Detentores de Imóveis Rurais;

III - Cadastro de Arrendatários e Parceiros Rurais;

IV - Cadastro de Terras Públicas;

V - Cadastro Nacional de Florestas Públicas.

$\S 2^{\circ}$ Fica criado o Cadastro Nacional de Imóveis Rurais - CNIR, que terá base comum de informações, gerenciada conjuntamente pelo INCRA e pela Secretaria da Receita Federal, produzida e compartilhada pelas diversas instituições públicas federais e estaduais produtoras e usuárias de informações sobre o meio rural brasileiro (BRASIL, 1972).

\subsection{Georreferenciamento de Imóveis Rurais}

Para fins de controlar as alienações e algumas transformações de direito que são publicadas no Registro (RAMBO et al, 2006), a Lei 10.267/2001 alterou a Lei 6.015/1973 (Lei dos Registros Públicos - LRP), criando especificamente para fins de Registro, a necessidade de georreferenciamento em certos casos em que há necessidade de melhor qualidade na descrição dos imóveis rurais.

Numa tentativa de liquidar com a grilagem de terras, o INCRA fiscaliza o procedimento de alteração na descrição dos imóveis rurais, ao mesmo tempo em que tem feito a discriminação entre as terras públicas e as terras privadas. Para evitar a sobreposição de títulos da propriedade, o INCRA também exige e fiscaliza o georreferenciamento dos vértices dos limites de imóveis rurais:

Lei $6.015 / 1973$, art. $176, \S 3^{\circ}$ Nos casos de desmembramento, parcelamento ou remembramento de imóveis rurais, a identificação prevista na alínea $a$ do inciso II do $\S 1^{\circ}$ será obtida a partir de memorial descritivo, assinado por profissional habilitado e com a devida Anotação de Responsabilidade Técnica - ART, contendo as coordenadas dos vértices definidores dos limites dos imóveis rurais, geo-referenciadas ao Sistema Geodésico Brasileiro e com precisão posicional a ser fixada pelo INCRA [...].

$\S 4^{\circ}$ A identificação de que trata o $\S 3^{\circ}$ tornar-se-á obrigatória para efetivação de registro, em qualquer situação de transferência de imóvel rural, nos prazos fixados por ato do Poder Executivo. [...]

Art. 225, § $3^{\circ}$ Nos autos judiciais que versem sobre imóveis rurais, a localização, os limites e as confrontações serão obtidos a partir de memorial descritivo assinado por profissional habilitado e com a devida Anotação de Responsabilidade Técnica - ART, contendo as coordenadas dos vértices definidores dos limites dos imóveis rurais, geo-referenciadas ao Sistema Geodésico Brasileiro e com precisão posicional a ser fixada pelo INCRA [...] (BRASIL, 2004, p. 1307 e 1315).

Para fins de regulamentar as exigências da Lei 10.267/2001, o INCRA tem publicado, já em $2^{\text {a }}$ edição Revisada, a Norma Técnica para Georreferenciamento de Imóveis Rurais, específica para fins de identificação do imóvel (Lei 6.015/1973, Art, 176, § 1º, II, 3), resultando em alterações na descrição de imóveis rurais no Registro (Lei 6.015/1973, Art. 176, $\S \S 3^{\circ}$ e $4^{\circ}$; Art. 225, $\S 3^{\circ}$ ).

Assim, parece que a Lei do Georreferenciamento Rural (Lei 10.267/2001) veio para resolver o problema da grilagem de terras. Mas para controlar e evitar a grilagem seria necessária uma análise contínua do território, com a existência de uma cartografia envolvendo todos os imóveis de uma região, o que está difícil de ocorrer com essa legislação, cuja implantação completa está cada vez mais postergada, dando tempo à ocorrência de novas grilagens.

Mas por que se fala em cadastro georreferenciado de imóveis rurais, se na letra da Lei consta que o procedimento é o da identificação georreferenciada da descrição de imóveis rurais?

Se a competência para o Cadastro é do INCRA, por que no Decreto 4.449/2002 (art. $9^{\circ}, \quad \S \S 1^{\circ}$ a $3^{\circ}$ ) 
inicialmente constou que é o Registro quem cadastraria as coordenadas georreferenciadas, informando posteriormente ao INCRA como é que o imóvel ficou? Em estudos anteriores já constatamos a estranha confusão conceitual na legislação:

Talvez as coordenadas apresentadas nas plantas de imóveis rurais ainda sejam cadastradas pelo INCRA (o que é de se esperar que ocorra) antes delas ingressarem no RI. Na legislação, porém, consta o contrário. O processo se inicia com o INCRA certificando a inexistência de imóvel cadastrado por georreferenciamento na área abrangida pelo memorial apresentado ( $\operatorname{art} 9^{\circ}, \S 1^{\circ}$ ). Os limites e confrontações medidos pelo profissional habilitado são indicados pelo proprietário (ao Registro) e o INCRA (inicialmente) não precisa reconhecer o domínio e exatidão desses limites $\left(\operatorname{art.} 9^{\circ}, \S 2^{\circ}\right)$.

As informações georreferenciadas que chegarem (no Registro) por primeiro terão ingresso facilitado no RI (art. $9^{\circ}, \S 3^{\circ}$ ) (o georreferenciamento de outros imóveis posteriormente seriam barrados no Registros, caso essas informações fossem incompatíveis com as anteriormente já 'cadastradas' no Registro). Tal dispositivo jurídico é equivocado ao fazer o Cadastro depender dos atos praticados no Registro. Afinal, as informações técnicas que ingressam no Registro devem ser previamente analisadas e certificadas, além de ser tecnicamente absurda e juridicamente utópica a pretensão de que o imóvel sofra mudanças no Registro (RAMBO, 2005, p. 101). (Observações e grifo nossos).

$\mathrm{O}$ art. $9^{\circ}$ e seus parágrafos na versão original do Decreto 4.449/2002 é uma afronta ao bom senso, ao permitir que qualquer cidadão podia introduzir no Registro coordenadas fraudulentas (griladas), viabilizando que um pequeno imóvel rural podia ser indevidamente transformado em um imenso imóvel georreferenciado, o qual já estaria legalizado no Registro para ter prioridade em relação às coordenadas verdadeiras de outros imóveis que tentariam ingressar com o georreferenciamento no Registro posteriormente. Essa confusão é difícil de ser resolvida sem apoio em um cadastramento sistemático que produza uma cartografia que apresente a continuidade dos imóveis.

Felizmente a possibilidade de se continuar com a introdução de falsas coordenadas georreferenciadas no Registro de Imóveis foi eliminada pelo Decreto $\mathrm{n}$. 5.570/2005, o qual acrescentou no Decreto n. 4.449/2002 o seguinte dispositivo:

Art. $9^{\circ}, \S 9^{\circ}$ Em nenhuma hipótese a adequação do imóvel às exigências do art. $176, \S \S 3^{\circ}$ e $4^{\circ}$, e do art. $225, \S 3^{\circ}$, da Lei n. 6.015 , de 1973 , poderá ser feita sem a certificação do memorial descritivo expedida pelo INCRA (BRASIL, 2005).

A Lei do Georreferenciamento (Lei 10.267/2001) alterou dispositivos da Lei n. 6.015/1973 (LRP), estabelecendo que, nos casos de desmembramento, parcelamento ou remembramento de imóveis rurais e na transferência da propriedade (LRP, art. 176, § $4^{\circ}$ ), a identificação do imóvel rural terá as coordenadas de seus vértices georreferenciadas ao Sistema Geodésico Brasileiro, com precisão fixada pelo INCRA (BRASIL, 2004, LRP, art. 176, § $3^{\circ}$, p. 1307).

$\mathrm{O}$ art. 10 do Decreto n. 4.449/2002, inicialmente previu que a necessidade de georreferenciamento, nos casos da alienação de imóveis, teriam prazos fixados por ato do Poder Executivo que venceriam em um máximo de
3 anos. Posteriormente o Decreto n. 5.570/2005 mudou esses prazos, alterando para um máximo de 8 anos. Esse prazo máximo já está prorrogado pelo Decreto n. $7.620 / 2011$ para um total previsto de 20 anos.

O prorrogamento sistemático nos prazos fixados para o georreferenciamento tem ocorrido devido às conhecidas e verdadeiras dificuldades técnicas, financeiras e de formação de pessoal qualificado na quantidade requerida aos procedimentos necessários para se cumprir as exigências da legislação registral (Lei 6.015/1973).

Tem sido impossível de se atender a demanda do sistema de georreferenciamento num curto prazo, provando que essa sistemática é totalmente inadequada para se produzir de imediato um Cadastro Rural nos moldes tradicionais, que contenha a necessária e tão desejada cartografia contínua, apresentando a totalidade dos imóveis em uma região para viabilizar o planejamento regional.

Tendo publicado em Rambo (2000 e 2011) duas propostas defendendo a retificação administrativa da descrição de imóveis, ficamos à vontade para afirmar que a retificação é um sistema que atualiza a descrição de imóveis sempre que houver necessidade de conhece-los com melhor precisão: por ocasião de parcelamento, de unificação, de subdivisão, da aprovação do projeto de edificação e até por ocasião da alienação, se as regras assim o exigirem.

A sistemática funciona com base no princípio da instância, segundo o qual tudo depende da iniciativa do interessado. Assim, a medição de um lote ou a emissão de uma certidão no CI (Cadastro Imobiliário) ou a averbação no RI (Registro de Imóveis) só ocorre a pedido de um interessado em que isso aconteça (RAMBO, 2000, p. 156). (Observações nossas).

Do mesmo modo, o Georreferenciamento também é um levantamento aleatório de imóveis isolados, destinado à retificação administrativa georreferenciada de imóvel (RAMBO, 2011), sistema perfeitamente adequado para a atualização cadastral, exatamente na medida da necessidade de se descrever imóveis com melhor precisão no Registro e segundo o princípio da instância, o qual tem sido aplicado com sucesso em vários setores da administração pública. O Decreto 4.449/2002, ao regulamentar a Lei 10.267/2001 ratifica isso:

Art. $7^{\circ}$ Os critérios técnicos para implementação, gerenciamento e alimentação do Cadastro Nacional de Imóveis Rurais serão fixados em ato conjunto do INCRA e da Secretaria da Receita Federal. [...] $\S 4^{\circ}$ As instituições gerenciadoras do CNIR poderão firmar convênios específicos para o estabelecimento de interatividade dele com as bases de dados das Administrações Públicas dos Estados, do Distrito Federal e dos Municípios. [...]

Art. $8^{\circ}, \S 2^{\circ}$ O INCRA proporcionará os meios necessários para a identificação do imóvel rural, devendo o ato normativo conjunto de que trata o art. $7^{\circ}$ deste Decreto estabelecer os critérios técnicos e procedimentos para a execução da medição dos imóveis para fim de registro imobiliário [...]

Art. $9^{\circ}, \S 5^{\circ} \mathbf{O}$ memorial descritivo, que de qualquer modo possa alterar o registro, resultará numa nova matrícula [...]. (Destaques nossos). 


\subsection{Cadastro Ambiental Rural}

A Lei 12.651/2012 dispõe sobre a proteção da vegetação nativa, revoga o Código Florestal (Lei 4.771/1965) e, na falta de cartografia contínua disponível para todo o país, criou o Cadastro Ambiental Rural CAR obrigatório para todos os imóveis rurais (art. 29), cuja inscrição o proprietário ou possuidor do imóvel deverá efetuar preferencialmente no órgão ambiental municipal ou estadual (art. 29, § $1^{\circ}$ ), sem eliminar a necessidade de cadastramento junto ao CNIR (art. 29, § $2^{\circ}$ ) (BRASIL, 2012a).

O Decreto 7.830/2012, ao regulamentar a Lei 12.651/2012, determina que:

Art. $3^{\circ}$ Fica criado o Sistema de Cadastro Ambiental Rural - SICAR, com os seguintes objetivos:

I - receber, gerenciar e integrar os dados do CAR de todos os entes federativos;

II - cadastrar e controlar as informações dos imóveis rurais, referentes ao seu perímetro e localização [...] IV - promover o planejamento ambiental e econômico do uso do solo e conservação ambiental no território nacional $[\ldots]$

$\S 4^{\circ} \mathrm{O}$ Ministério do Meio Ambiente disponibilizará imagens destinadas ao mapeamento das propriedades e posses rurais para compor a base dos dados do sistema de informações geográficas do SICAR, com vistas a implantação do CAR (BRASIL, 2012b).

O Decreto 7.830/2012 determina que o proprietário deverá fornecer a planta georreferenciada do perímetro do imóvel (art. $5^{\circ}$ ) e que, no caso de pequena propriedade ou posse rural familiar, essa planta pode ser substituída por um croqui que indique o perímetro do imóvel (art. $8^{\circ}$ ):

-Planta é a "representação gráfica plana, em escala mínima de 1:50.000, que contenha particularidades naturais e artificiais do imóvel rural" (art. $2^{\circ}$, IX).

-Croqui é a "representação gráfica simplificada da situação geográfica do imóvel rural, a partir da imagem de satélite georreferenciada disponibilizada via SICAR [...]" (art. $\left.2^{\circ}, \mathrm{X}\right)$ (BRASIL, 2012b).

A Lei 12.651/2012 ainda determina que:

Art. $1^{\circ}$, Parágrafo único. Tendo como objetivo o desenvolvimento sustentável, esta lei atenderá aos seguintes princípios: [...]

IV - responsabilidade comum da União, Estados, Distrito Federal e Municípios, em colaboração com a sociedade civil, na criação de políticas para a preservação e restauração da vegetação nativa e de suas funções ecológicas e sociais nas áreas urbanas e rurais (BRASIL, 2012a).

A reserva legal tem registro obrigatório no órgão ambiental competente, mediante inscrição no CAR (Lei 12.651/2012, art. 18), cujo ato desobriga a averbação da Reserva Legal no Registro de Imóveis (art.18, § $4^{\circ}$ ).

\subsection{Cadastro Territorial Multifinalitário}

Ministério das Cidades, através da Portaria Ministerial $n^{\circ} 511$, de 07 de dezembro de 2009, esclarece que:

Art. $1^{\circ} \mathrm{O}$ Cadastro Territorial Multifinalitário (CTM), quando adotados pelos municípios, será o inventário territorial oficial e sistemático do município e será embasado no levantamento dos limites de cada parcela, que recebe uma identificação numérica inequívoca (BRASIL, 2009).
Brasil (2009) define vários pontos importantes para que um Cadastro Territorial seja Multifinalitário:

"O CTM deve ser utilizado como referência básica para qualquer atividade de sistemas ou representações geoespaciais do município", devendo atender às necessidades sociais, ambientais, econômicas, da Administração Pública e de segurança jurídica da sociedade (Art. $6^{\circ}$ e seu Parágrafo único), sendo que "toda e qualquer porção da superfície territorial no município deve ser cadastrada" (art. $\left.3^{\circ}\right)$.

Enquanto os limites para fins de Registro devem ser obtidos com precisão de levantamentos topográficos e geodésicos $\left(\S 1^{\circ}\right.$ do art. 13), os limites físicos podem ser levantados tanto por métodos topográficos, quanto por métodos geodésicos, fotogramétricos ou outros $\left(\S 2^{\circ}\right.$ do art. 13) que obedeçam aos padrões estabelecidos para a Infraestrutura Nacional de Dados Espaciais - INDE e às normas relativas à Cartografia Nacional, de acordo com o art. $4^{\circ}$ do Decreto 6.666/2008 (art. 14).

A Carta Cadastral está definida como representação cartográfica do levantamento sistemático territorial do Município (art. $8^{\circ}$ ).

Os munícipes e os órgãos municipais, estaduais e federais poderão ter acesso a dados do CTM (art. 18). Para ser multifinalitário, o CTM deve ser modelado de modo a atender às necessidades dos diferentes usuários, atuais ou potenciais, com base em um único sistema de referência e um único identificador para cada parcela (art. 21).

Por fim, as Diretrizes orientam que a multifinalidade do CTM é um processo evolutivo aberto, de integração gradativa dos diferentes temas e que deve ocorrer ao longo dos anos (art. 22).

Ainda, não se pode esquecer que a multifinalidade é potencializada pelo levantamento sistemático de todo o território do município (art. 27), viabilizando a avaliação atualizada do valor venal dos imóveis urbanos e rurais para fins fiscais ( $\$ 4^{\circ}$ do art. 16 e o art. 28), de modo a gerar incremento de receitas que possam financiar a implantação e manutenção do CTM (art. 19).

$\mathrm{Na}$ questão de levantamentos sintemáticos, além do CAR, interessa-nos estudar, a seguir, a implantação de Cadastro através da metodologia aerofotogramétrica.

Mas é bom lembrar o que a Constituição da República Federativa do Brasil determina sobre o ITR: Art. 153. Compete à União instituir impostos sobre: $[\ldots]$

VI - propriedade territorial rural; [...]

$\S 4^{\circ} \mathrm{O}$ imposto previsto no inc. VI do caput; $[\ldots]$

III - será fiscalizado e cobrado pelos Municípios que assim optarem, na forma da lei, desde que não implique redução do imposto ou qualquer outra forma de renúncia fiscal. [...]

Art. 158. Pertencem aos Municípios: [...]

II $-50 \%$ do produto da arrecadação do imposto da União sobre a propriedade territorial rural, relativamente aos imóveis neles situados, cabendo a totalidade na hipótese da opção a que se refere o art. 153, $§ 4^{\circ}$, III (BRASIL, 2004, p. 93, 94 e 100). 


\subsection{Cadastro por Aerofotogrametria no Brasil}

O cadastramento de imóveis por aerofotogrametria tem sido utilizado com sucesso em diversos países, sendo recomendado pela Mission Tecnica Alemana (1971) como adequado para planejar o desenvolvimento em áreas urbanas e rurais, devendo-se nestas diminuir as escalas de voo, na medida em que há redução na quantidade de imóveis em cada região a ser cadastrada.

\subsubsection{Método aerofotogramétrico em áreas urbanas}

Nas décadas 50 e 60 do século passado, a maioria das cidades brasileiras careciam de infraestrutura urbana, sendo comum na época os brasileiros conviverem em cidades com deficiências nas redes de água servida, de águas pluviais, de luz e falta de pavimentação nas ruas, sem citar a falta das redes de coleta do esgoto, as quais geralmente só tem sido implantadas mais recentemente.

No início da década de 70 o Brasil criou o SERFHAU - Serviço Federal de Habitação e Urbanismo, o qual cadastrou mais de 200 empresas para executarem os Cadastros Técnicos Municipais a partir da metodologia aerofotogramétrica, visando promover o planejamento urbano integrado das cidades.

As empresas receberam recursos do $\mathrm{BNH}-\mathrm{Banco}$ Nacional da Habitação, com financiamento a ser pago pelos municípios com dinheiro do IPTU - Imposto Predial e Territorial Urbano, posteriormente arrecadado a partir do próprio cadastramento efetuado para os imóveis urbanos, gerando vultuosa fonte de arrecadação.

$\mathrm{Na}$ época, ao constatar a inviabilidade econômica para os pequenos municípios contratarem o cadastramento dos imóveis em suas cidades, o Ministério da Fazenda criou o projeto CIATA - Convênio de Incentivo ao Aperfeiçoamento Técnico-Administrativo das Municipalidades, através do qual, a fundo perdido, financiou a execução de cadastros com qualidade técnica adequada e semelhante aos desenvolvidos através do SERFHAU.

A seguir foi publicada a Lei dos Registros Públicos - LRP (Lei n. 6.015/1973), criando a matrícula própria para os cartórios registrarem os direitos (propriedade) e averbarem suas alterações (ônus, reduzindo os direitos de propriedade) sobre cada imóvel e obrigando que, se o imóvel já estiver cadastrado, suas características devem ser indicadas como provenientes do órgão competente, citando-se o n. da sua inscrição cadastral, reconhecendo que a aerofotogrametria da época era adequada para fins de Registro (BRASIL, 1974).

Rambo (2000) demonstrou que a sistemática de retificação na matrícula, a partir de informações provenientes do CIU (Cadastro Imobiliário Urbano) foi exigida para todo o Brasil através da LRP, pela qual o legislador recusou na época a proposta de Carvalho (1998, p. Vii-viii, 395-407, 475-479) que em 1947 e depois em 1969 (Decreto-Lei n. 1.000/1969) tentou implantar o Cadastro Urbano e Rural como sendo um setor do RI (Registro de Imóveis). A proposta contém alternativas para superar a quase inexistência, no Brasil, de Cadastros naquela época (RAMBO, 2005, p. 98-99).

Assim, constata-se que o Cadastro Imobiliário Urbano é cartográfico e multifinalitário, pois além do planejamento, serve para fins do Registro de Imóveis e para fins de incremento na arrecadação municipal.

\subsubsection{Método aerofotogramétrico em áreas rurais}

No Brasil, atualmente boa parte dos imóveis apenas tem dados declaratórios no CIR, embora o INCRA e os órgãos estaduais possuem algumas áreas cadastradas através do método aerofotogramétrico, cuja utilização foi desmotivada no Brasil, porque antes da Lei 10.267/2001, os cartórios costumavam não aceitar essas informações para fins de retificação no Registro.

Embora a legislação autorize os municípios a assumirem a responsabilidade pelo cadastramento de imóveis rurais, isso tem sido inviável porque o ITR cobrado pela Secretaria da Receita Federal tem valor irrisório, inviabilizando o retorno de eventual investimento dos municípios na realização e no controle do Cadastro de Imóveis Rurais:

O imposto sobre a propriedade territorial rural (ITR) arrecadado em todo Brasil, nos 12 meses de 2007, foi de R\$ 379 milhões de reais, valor menor que dois meses de recolhimento do IPTU (Imposto Predial Territorial Urbano) só na cidade de São Paulo. Portanto, um grande presente para o latifúndio (ANDES-SN, 2013).

$\mathrm{Na}$ qualidade do economista e aerofotogrametrista de Botucatu-SP, que desde 1946 recomendou para que o Brasil adotasse a bem sucedida sistemática de aerofotogrametria para o cadastramento de imóveis urbanos, Balata (1984 e 1998) recomenda desde 1968 que a mesma sistemática deve ser implantada em escalas adequadas também para os imóveis rurais. Ele deixa bem claro que a existência de uma cartografia cadastral facilita muito para organizar o planejamento e alavancar o desenvolvimento de uma região ou de um país.

\subsection{Grilagem de Terras}

Há grupos que por vezes se aproveitam de questões controversas para incentivarem doutrinas que possam ser manipuladas em favor de interesses específicos ou da manutenção do status a quo, no qual é fácil cometer crimes contra a sociedade. Para esses grupos pode não interessar a existência de um Cadastro cartográfico, com a continuidade dos imóveis rurais em cada município.

O cadastramento com continuidade cartográfica efetivamente não tem acontecido para todo o país. Nas regiões mais desenvolvidas, há uma excessiva preocupação com a precisão do georreferenciamento, que seria requisito necessário para o cadastro de imóveis. Isso entrava o cadastramento imediato e contínuo no país. Enquanto isso, não sobra tempo nem tem cartografia para se controlar o caos da grilagem que ocorre em algumas regiões mais afastadas:

Tais exigências legais certamente já deveriam ser barreira para muitas transações em todo o país, todavia pouca publicidade tem sido dada à legislação e os Cartórios de Registro de Imóveis olimpicamente ignoram a lei 10.267 (ÉLERES, 2007, p. 129).

Essa confusão sempre foi adequada para a prática da grilagem de terras. Ferreira (1993, p. 279) define 
grilagem como um sistema utilizado para se apossar ou tornar-se dono aparente de terras alheias mediante títulos falsos, envolvendo tanto terras públicas quanto privadas.

Forster (2003, p. 129-130) refere-se às grilagens na faixa de fronteira. Carvalho (1998, p. 381) informa que o título fraudulento (grilo) de terras da União, de Estados e de Reservas Indígenas é formado com a complacência ou cumplicidade do Registro.

Rambo (2005, p. 93) indica uma sistemática de grilagem das terras de marinha, praticada a partir de meados do século XX, em Florianópolis, no litoral Norte da Ilha de Santa Catarina:

O processo iniciava com o registro da escritura pública de declaração da posse mansa e pacífica, ocorrendo posteriormente a transformação gradativa dessa posse em propriedade, através de registros sucessivos parcelando e loteando o imóvel sem qualquer referência a plantas, memoriais descritivos, autorização municipal ou destinação de áreas públicas ao Município, exceto pequenas ruas.

Fachin e Keppen Filho (198-?, p. 35-43) informam que as terras públicas griladas podem ser retomadas pelo governo, através de processos discriminatórios, pelos quais serão separadas as terras públicas das privadas. Esse procedimento pode ser conveniente para o país manter a soberania sobre as terras da Amazônia, envolvendo interesses de Organizações Não Governamentais - ONGs e de latifundiários, mas deixa grande parte da população insegura, já que muitas terras podem ser declaradas devolutas, de marinha ou da faixa de fronteira.

Segundo Moreno (1984, p. 419-420), será difícil viabilizar a reforma agrária e dar segurança real à posse, sem a existência de um cadastro cartográfico e contínuo, apresentando todos imóveis de uma determinada região.

Mas só a existência de uma cartografia contínua, na qual é evidentemente fácil analisar a vizinhança dos imóveis, não é suficiente para resolver o problema da grilagem de terras no Brasil:

A Lei 6.015/1973 ainda aceita que a descrição dos imóveis urbanos (dos quais as prefeituras tem cartografia cadastral) pode ser "corrigida" (por retificação) no Registro, a partir da simples planta de um profissional da topografia, sem exigir a apresentação do devido controle de qualidade do serviço. Esse controle de qualidade deve ser comprovado pela apresentação da certificação (Certidão) emitida pelo órgão cadastral competente, após o correspondente projeto ser aprovado pelo Município.

\section{QUALIDADE CARTOGRÁFICA NO CADASTRO}

No Brasil, a cartografia cadastral urbana normalmente tem sido realizada através da metodologia aerofotogramétrica. Por outro lado, para imóveis rurais ainda funciona o Cadastro de Imóveis Rurais, realizado através de dados literais declaratórios, carecendo-se de uma cartografia contínua, que apresente a sequência dos imóveis em cada região.

Por outro lado, para fins de alteração na descrição de imóveis rurais no Registro, exige-se georreferenciamento por GNSS com precisão de $0,50 \mathrm{~cm}$, devendo-se respeitar normas do INCRA específicas para essa atividade.
Pode-se afirmar que o ponto crítico da norma, é que evidenciou muito as potencialidades da Tecnologia GPS para o georreferenciamento dos vértices das propriedades rurais, omitindo-se outras possibilidades, como a Fotogrametria e mesmo o levantamento com Estações totais, entre outros (LOCH, 2007, p. 1287).

Loch (2007, p. 1282) estranha que a cultura cartográfica brasileira esteja atrelada à questão da precisão necessária aos mapas, despreocupando-se com a necessidade de mapas temáticos que retratem a ocupação do território simultaneamente ao nível federal, estadual e principalmente municipal.

Em experiências que se desenvolveu em perícias, utilizando-se de produtos cartográficos gerados a partir de um filme fotogramétrico de um vôo 1/8.000, escanerizado com uma resolução geométrica de 5 microns, consegue-se a medição de pontos na superfície terrestre com a precisão espacial melhor que 50 centímetros. No caso da perícia a definição de um ponto pelo método fotogramétrico passa a ter maior valor do que aquele levantado por GPS, uma vez que é possível fazer uma série de associações de vizinhança ao ponto de interesse (LOCH, 2007, p. 1287).

Infelizmente muitos profissionais estão deixando a aerofotogrametria em segundo plano, entendendo que essa metodologia não seria adequada para a realização do cadastramento de imóveis rurais, porque não teria a precisão legalmente exigida para as finalidades registrais.

Esses profissionais da área de agrimensura passaram a defender na doutrina que a Norma de Georreferenciamento de Imóveis Rurais - NGIR seria uma regra cuja precisão deveria ser respeitada em quaisquer levantamentos cadastrais:

A NGIR estabelece em $0,5 \mathrm{~m}$ a precisão posicional para cada par de coordenadas, relativas a cada vértice definidor do limite do imóvel rural, nos levantamentos cadastrais. Enquanto na área urbana, até então, não se tem ainda uma definição de precisão para a determinação do limite dos imóveis (SOARES, 2010, p. 38).

Há décadas discute-se que todos os levantamentos cadastrais deveriam ter uma única acurácia para os imóveis rurais e outra para os imóveis urbanos. Mas a questão é controversa e esse entendimento pode ser um antigo e grande engano que o presente trabalho pretende esclarecer.

O Código de Processo Civil (Lei 5.869/1973), por exemplo, ao tratar da Ação de Divisão e da Demarcação de terras particulares, define a precisão necessária para essa atividade específica:

Art. 960. Nos trabalhos de campo observar-se-ão as seguintes regras: [...]

II - empregar-se-ão os instrumentos aconselhados pela técnica; $[\ldots]$

Art. 961, Parágrafo único. As escalas das plantas podem variar entre os limites de 1 para 500 a 1 para 5.000 conforme a extensão das propriedades rurais, sendo admissível a de 1 , para 10.000 nas propriedades de mais de 5 quilômetros quadrados (BRASIL, 2004, p. 851-852).

Soares (2010, p. 40), talvez não se atentando de que para cada finalidade há necessidade de uma acurácia específica, prosseguiu com o raciocínio:

A definição de um valor para a acurácia, segundo Brandão (2003), deve também atender às exigências da Lei 10.406 - que instituiu o novo Código Civil, que estabelece o erro máximo de 5\% (um vigésimo) na área de um imóvel a venda. Se a diferença for superior a 
esse percentual, o comprador terá o direito de exigir o complemento da área ou abatimento proporcional no preço (SOARES, 2010, p. 40).

Rambo (2000, p. 88) constatou que é normal os tribunais não limitarem o aumento da área em retificação a um vinte avos, pelo que se deduz que o limite de 5\% só serve para o caso específico previsto no Código Civil CC. Já sabendo da procura por um limite de acurácia para imóveis urbanos, concluiu:

Portanto esse limite de $5 \%$ no CC não é o erro técnico máximo de precisão admitido por lei aos profissionais responsáveis nos serviços de medições fundiárias (RAMBO, 2000, p.88).

E Rambo (2000, p. 88-89) finaliza:

Como responsáveis técnicos, esses profissionais se obrigam a respeitar em quaisquer de seus serviços técnicos, os erros técnicos máximos admitidos por normas técnicas como a de Execução de levantamento topográfico NBR $13133 \quad$ (ASSOCIAÇÃO BRASILEIRA DE NORMAS TÉCNICAS, 1994), e o Decreto n. 89.137, de 20 de junho de 1984, que dispõe sobre Instruções reguladoras das normas técnicas da cartografia nacional, quanto aos padrões de exatidão (BRASIL, 1984), por exemplo.

Do exposto acima conclui-se que para cada tipo de procedimento (retificação judicial; presunção da aquisição de coisa certa; levantamento topográfico; elaboração de mapas) deve-se respeitar a qualidade exigida pelo órgão interessado nas informações, cuja acurácia será definida e adequada para as finalidades desejadas.

Para o Cadastro Ambiental Rural, por exemplo, o legislador concluiu que a precisão da planta pode ser de 1:50.000, servindo até mesmo o desenho de um croqui efetuado a partir de uma determinada imagem de satélite georreferenciada. Esse procedimento é aceitável, já que a necessidade da cartografia é imediata, visando apenas controlar o meio ambiente e 1:50.000 é bem melhor do que continuar sem cartografia. Para se obter a qualidade desejada, devem-se escolher os equipamentos e o tipo de levantamento que for mais adequado, para cada um dos quais deverá haver uma norma técnica específica.

Por outro lado, essa questão de precisão cartográfica é muito relativa, variando as opiniões ao longo do tempo, conforme os interesses envolvidos em cada época:

- Por que até há pouco tempo os cartórios funcionaram a partir de informações descritivas dos imóveis, sem qualquer necessidade de precisão, e de uma hora para outra exigem a necessidade de uma precisão com metodologia que a sociedade não dá conta de produzir e o governo tem dificuldades para fiscalizar?

- Por que há pouco tempo atrás não podíamos aproveitar o cadastramento aerofotogramétrico de boa qualidade para fins de retificação no Registro e agora o cadastramento por aerofotogrametria parece estar (novamente) entravado pela necessidade registral de um procedimento demorado que depende de equipamentos e de profissionais que o país não dispõe em quantidade "adequada"?

- Se o país precisa de um CIR, mais um CNIR, mais um CAR e mais um CTM, por que estamos sem todos eles?

- Se nossa necessidade urgente é a cartografia contínua, por que estamos mais preocupados com uma precisão de imóveis avulsos que antes nunca era necessária no Registro?

- Se o ITR está sendo arrecadado com base em informações descritivas, por que não podemos cobrá-lo com base nas informações cartográficas de um CAR?

- Se não temos um CTM no Município, por que não serve adotarmos como base inicial o CAR, já que, nos casos da necessidade de melhor precisão, podemos medir em campo, atualizando a descrição correta no CAR e certificando a qualidade do produto para fins de retificação no Registro, formando um processo de dinâmica sistemática no aperfeiçoamento na descrição de imóveis?

Com a palavra, para ajudar nas conclusões, os ensinamentos de Hélio Beltrão, Ex-Ministro Extraordinário para a Desburocratização.

\section{CONCLUSÃO}

Tradicionalmente costumávamos imaginar que um Cadastro, para ser multifinalitário, deveria possuir uma base cartográfica completa e com acurácia adequada para atender às mais exigentes finalidades. Entretanto,

O desenvolvimento nacional é uma luta contra o tempo. Nossa prioridade é a urgência e não a perfeição (BELTRÃO, 1984, p. 127).

Desse modo, não podemos ficar esperando que a sistemática de georreferenciamento aleatório de imóveis avulsos nos forneça um cadastramento contínuo que parece estar cada vez mais longe de ser concluído.

É preciso acabar, na Administração, com o hábito de imaginar que uma coisa só acontece realmente depois que se transforma em documento. No Brasil, a presença do defunto merece menos fé do que a certidão de óbito (BELTRÃO, 1984, p. 127).

A opção pelo georreferenciamento tem como meta livrar a sociedade da insustentável grilagem de terras. Porém,

Noventa e nove por cento dos brasileiros não são desonestos nem falsários. A excessiva exigência burocrática só serve para dificultar a vida dos honestos sem intimidar os desonestos, que são especialistas em falsificar documentos (BELTR ̃̃O, 1984, p. 126).

Provavelmente estejamos "com a carroça na frente dos bois":

A verdade é que o Brasil já nasceu rigorosamente centralizado e regulamentado. Desde o primeiro instante, tudo aqui aconteceu de cima para baixo e de trás para diante (BELTRÃO, 1984, p. 125).

A verdade é que precisamos urgentemente de um Cadastro simples, com cartografia maleável que suporte a possibilidade de compatibilizar informações produzidas a partir de metodologias e de escalas diferenciadas, produzidas na medida das possibilidades e das necessidades das administrações municipais. A tecnologia de hoje não deve apresentar dificuldades para viabilizar que isso aconteça quase que de imediato em nosso país.

Trata-se de promover o que denominamos de "aterrizagem no Brasil real". E que temos descrito da forma seguinte:

Existe entre nós uma curiosa inclinação para raciocinar, legislar e administrar tendo em vista um país imaginário, que não é o nosso; um país denominado pelo exercício fascinante do planejamento abstrato, pela ilusão de ótica das decisões centralizadas e das 
concepç̃es macroeconômicas, pelo deslumbramento ante as soluções importadas, sofisticadas e onerosas, incompatíveis com a nossa realidade e com os modestos padrões de renda de nosso povo (BELTRÃO, 1984, p. 12)

Essa dinâmica cartográfica, compatibilizando informações de qualidades variadas, inclusive tem funcionado há décadas para o mapeamento de imóveis urbanos na cidade de Pato Branco-PR, onde o Cadastro foi feito a partir de aerofotogrametria e/ou de outras medições às vezes apressadas e com baixa qualidade. Sempre que há necessidade de melhor precisão nos dados de um imóvel, faz-se o recadastramento a partir de vistoria local, inclusive certificando-se as informações para fins de retificação no Registro, tal como ocorre hoje com o georreferenciamento de imóveis rurais.

A descentralização constitui, na verdade, a melhor maneira de assegurar a eficácia e reduzir o custo dos programas federais. Nenhum plano nacional poderá ser realmente eficaz se não tiver sua execução amplamente descentralizada e se não puder engajar, desde a fase de sua elaboração, a participação dos mecanismos administrativos locais, que estão naturalmente melho habilitados a identificar e resolver os problemas da maneira mais rápida e peculiar a cada caso (BELTRÃO, 1984, p. 26-27).

Visto deste modo, pode-se concluir que um bom Cadastro, para realmente ser multifinalitário, não deve ser realizado apenas visando os fins de Registro, mas principalmente deve ser montado de imediato também para finalidades mais simples e nobres, tais como viabilizar uma visualização cartográfica para fins de uma justa tributação e de uma mínima possibilidade de se realizar o necessário planejamento.

O Programa de Desburocratização nada tem de utópico. Não pretende mudar a cultura de nosso povo e sim o comportamento da Administração Pública, eliminando o descompasso cultural entre este e o da maioria do povo brasileiro (BELTRÃO, 1984, p. 126).

A viabilidade para a implantação de um projeto dessa importância, depende apenas de a União despertar de imediato o interesse financeiro dos Municípios:

O esperado e muito bem bolado Cadastro Territorial Multifinalitário - CTM, deve ser implantado a nível municipal, inicialmente a partir do sistema previsto para o bem vindo Cadastro Ambiental Rural - CAR. Aos poucos, essas informações cartográficas podem ser substituídas por informações com melhor acurácia, registrando-se a qualidade possuída por cada informação disponibilizada no sistema, de modo que essa qualidade possa ser melhorada e/ou certificada a qualquer tempo.

Uma reforma tributária que favoreça os Estados e municípios, estabelecendo uma partilha mais adequada de tributos e recursos, é absolutamente necessária. Mas não é suficiente. É imprescindível que ela se faça acompanhar de uma clara redefinição de competência entre os vários níveis da Federação, fortalecendo-se não apenas a receita como a autonomia e a capacidade dos municípios para decidirem os assuntos de seu imediato interesse (BELTRÃO, 1984, p. 24).

Assim, o Imposto sobre a Propriedade Territorial Rural - ITR deve acompanhar o processo e ser imediatamente municipalizado, conforme já permitido na legislação maior. O governo federal deve rever e redefinir as alíquotas para todo o território nacional, mas cada Município deverá avaliar os imóveis de sua própria jurisdição, aos moldes do que já ocorre com eficácia para o Imposto Predial e Territorial Urbano - IPTU.

\section{AGRADECIMENTOS}

Ao Grupo de Pesquisa e Estudos em Geomática GEPG/UTFPR do Campus Pato Branco, por instigar o debate e os estudos neste tema.

\section{REFERÊNCIAS}

ANDES-SN. Campanha de Denúncia da Injustiça Tributária no Brasil. Contribuição da Assembleia Geral da Seção Sindical do ANDES-SN na UFRGS. In: CONGRESSO do ANDES-Sindicato Nacional, 32 ${ }^{\circ}$, 2013, Rio de Janeiro. Caderno de Textos. Rio de Janeiro, ANDES-SN, 2013. TEXTO 16, p. 64.

BALATA, Kenard da Silva. Cadastro e registro de terras no Brasil. In: SIMPÓSIO INTERNACIONAL DE EXPERIÊNCIA FUNDIÁRIA, 1984, Salvador. Anais... Brasília : INCRA, 1984. 614 p. p. 441-470.

Planejamento rural, cadastros e descentralização

da reforma agrária. In: CONGRESSO BRASILEIRO

DE CADASTRO TÉCNICO MULTIFINALITÁRIO, 3o.; ENCONTRO DE CADASTRO TÉCNICO MULTIFINALITÁRIO PARA OS PAÍSES DO MERCOSUL, $1^{\circ}$, 1998, Florianópolis. Anais... Florianópolis: UFSC, 1998. 1 CD-ROM.

BELTRÃO, Hélio. Descentralização e liberdade. $2^{\mathrm{a}}$ ed. Rio de Janeiro : Record, 1984. 173 p.

BRASIL. Lei n. 5.868, de 12/12/1972: cria o Sistema Nacional de Cadastro Rural, e dá outras providências. Disponível em <http://www.planalto.gov.br/ccivil_03/leis/L5868.htm $>$. Acesso em: 15 mar. 2013.

Nova Lei de Registros Públicos: Lei n. 6015, de 31/12/1973. GB: Auriverde, 1974. 100 p.

Ministério da Agricultura e Reforma Agrária. Instituto Nacional de Colonização e Reforma Agrária. Diretoria de Cadastro e Tributação. Sistema Nacional de Cadastro Rural. Cadastro de Imóveis Rurais: Manual de Orientação. Brasília : INCRA, [200-?]. 32 p.

Constituição Federal, Código Civil (2002 e 1916), Código de Processo Civil, Código Penal, Código de Processo Penal: legislação complementar fundamental. Organização, editoria jurídica da Editora; coordenador da revisão José Roberto Neves Amorim; equipe de revisão, Vanda Lúcia Neves Amorim... et al. 3a . ed. Barueri : Manole, 2004. 1923 p. (Coleção 5 em 1).

Decreto n. 5.570, de 31/10/2005: dá nova redação a dispositivos do Decreto n. 4.449 , de 30 de outubro de 2002, e dá outras providências. Disponível em: <http://www.planalto.gov.br/ccivil_03/_Ato20042006/2005/Decreto/D5570.htm>. Acesso em: 11 mar. 2013.

Ministério do Desenvolvimento Agrário. Coletânea de legislação e jurisprudência agrária e correlata. Tomo I: dispositivos constitucionais, leis 
complementares, leis ordinárias, medidas provisórias e decretos-lei. Organizadores Joaquim Modesto Pinto Junior, Valdez Farias. Brasilia : MDA/NEAD, 2007. 711 p. (NEAD Especial; 7).

Ministério das Cidades. Diretrizes para a criação, instituição e atualização do Cadastro Territorial Multifinalitário nos municípios brasileiros: Manual de Apoio (Portaria Ministerial $\mathrm{n}^{\circ}$ 511, de 07 de dezembro de 2009). Brasília : MCidades/Lincoln Institute, 2009, 170 p. (Programa Nacional de Capacitação das Cidades).

Lei n. 12.651, de 25/05/2012a: dispõe sobre a proteção da vegetação nativa $[\ldots]$. Disponível em: <http://www.planalto.gov.br/ccivil_03/_Ato20112014/2012/Lei/L12651.htm>. Acesso em: 18 mar. 2013.

Decreto n. 7.830, de 17/10/2012b: dispõe sobre o Sistema de Cadastro Ambiental Rural, o Cadastro Ambiental Rural [..]. Disponível em: <http://www.planalto.gov.br/ccivil_03/_Ato20112014/2012/Decreto/D7830.htm>. Acesso em: 18 mar. 2013.

CARVALHO, Afrânio de. Registro de Imóveis: comentários ao sistema de registro em face da Lei n. 6.015, de 1973, com alterações da Lei n. 8.009, de 29.03.1990, e Lei n. 8.935, de 18.11.1994. 4. ed. ver. e atual. Rio de Janeiro : Forense, 1998. 511 p.

ÉLERES, Paraguassú. Cadastro de Imóveis Rurais e grilagem. In: Revista de Direito Agrário / Instituto Nacional de Colonização e Reforma Agrária. Ano 20 no 20. Brasília : INCRA, 2007. p. 121-130. Também diisponível em <www.incra.gov.br ; www.nead.org.br ; www.abda.com.br>.

FACHIN, Luiz Edson ; KEPPEN FILHO, Theodoro. A discriminatória administrativa sobre a Lei de Terras do Estado do Paraná. In: INSTITUTO DE TERRAS E CARTOGRAFIA DO ESTADO DO PARANÁ. Terras devolutas: processo discriminatório - doutrina e legislação. Curitiba : ITCF, 198-?. p.35-43.

FERREIRA, Aurélio Buarque de Holanda et al. Minidicionário da língua portuguesa. 3.ed. Rio de Janeiro : Nova Fronteira, 1993. 577 p.

FORSTER, Germano de Rezende. A privatização das terras rurais. Barueri : Manole, 2003. 160 p.

LOCH, Carlos. A realidade do Cadastro Técnico Multifinalitário no Brasil. In: SIMPÓSIO BRASILEIRO DE SENSORIAMENTO REMOTO, XIII, 2007, Florianópolis. Anais... Florianópolis : INPE, 21-26 abril 2007. p. 1281-1288.

MISSION TECNICA ALEMANA. Del levantamiento de Cadastro. Bajo dirección y responsabilidad del director Rudolf Elstner. San José : Edición Provisional, 1971. $182 \mathrm{p}$.

MORENO, Rafael. Cadastro e registro de terras. In: SIMPÓSIO INTERNACIONAL DE EXPERIÊNCIA FUNDIÁRIA, 1984, Salvador. Anais... Brasília : INCRA, 1984. 614 p. p. 417-425 p.

PEREIRA, Kátia Duarte; AUGUSTO, Moema José de Carvalho. O sistema geodésico brasileiro e a lei de georreferenciamento de imóveis rurais. In: GT
Cadastro e Lab FSG. CONGRESSO BRASILEIRO DE CADASTRO TÉCNICO MULTIFINALITÁRIO, $6^{\circ} ;$ ENCONTRO DE CADASTRO TÉCNICO MULTIFINALITÁRIO PARA OS PAÍSES DO MERCOSUL, $4^{\circ}$; ENCONTRO DE CADASTRO TÉCNICO MULTIFINALITÁRIO PARA OS PAÍSES DA AMÉRICA LATINA, 1º, 2004, Florianópolis. Anais... Florianópolis: Lab. FSG. / UFSC, 2004. 1 CD - ROM.

RAMBO, Jacir Antônio. Contribuição jurídica para a retificação administrativa georreferenciada de imóvel urbano nos registros de imóveis brasileiros. Jürgen Wilhelm Philips (Orient). 2011. 148 p. Dissertação (Mestre em Engenharia Civil) - Área de Concentração em Cadastro Técnico Multifinalitário e Gestão Territorial, UFSC, Florianópolis, 2011. Disponível em: <http://repositorio.ufsc.br/xmlui/handle/123456789/95 $116>$.

; et al. Transformação de imóveis e atualização de matrículas nas incorporações imobiliárias não registradas. In: GT Cadastro e Lab FSG. CONGRESSO BRASILEIRO DE CADASTRO TÉCNICO MULTIFINALITÁRIO, $7^{\circ}$; ENCONTRO DE CADASTRO TÉCNICO MULTIFINALITÁRIO PARA OS PAÍSES DO MERCOSUL, 5; ENCONTRO DE CADASTRO TÉCNICO MULTIFINALITÁRIO PARA OS PAÍSES DA AMÉRICA LATINA, 2º 2006, Florianópolis. Anais... Florianópolis: Lab. FSG. / UFSC, 2006. 1 CD - ROM.

RAMBO, Luiz Inácio. Retificação administrativa de limites, confrontações e áreas de terrenos urbanos junto ao Registro de Imóveis, a partir de dados do Cadastro Imobiliário Urbano. Carlos Loch (Orient.). 2000. 175 p. Dissertação (Mestre em Engenharia Civil) - Área de Concentração em Cadastro Técnico Multifinalitário, UFSC, Florianópolis, 2000. Disponível em: <http://repositorio.ufsc.br/xmlui/handle/123456789/78 895>. Acesso em 04 mar. 2013.

Uma proposta para conexão do Registro de Imóveis ao Cadastro Imobiliário Urbano. Carlos Loch (Orient.). 2005. 220 p. Tese (Doutor em Engenharia Civil) - Área de Concentração em Cadastro Técnico Multifinalitário e Gestão Territorial, UFSC, Florianópolis, 2005. Disponível em: <http://repositorio.ufsc.br/xmlui/handle/123456789/88 311>. Acesso em 04 mar. 2013.

SIMPÓSIO INTERNACIONAL DE EXPERIÊNCIA FUNDIÁRIA, 1984, Salvador. Anais... Brasília : INCRA, 1984. 614 p.

SOARES, Leandro Dilnei Viana. Avaliação do sistema cartográfico municipal. Carlos Loch (Orient.). 2010. 89 p. Dissertação (Mestre em Engenharia Civil) - Área de Concentração em Cadastro Técnico Multifinalitário, UFSC, Florianópolis, 2010. 